\title{
Depletion of Soil Water-Extractable Organic Matter With Long-Term Coverage by Impervious Surfaces
}

\author{
Yinghui Wang ${ }^{1,2,3+}$, Qiang Zhang ${ }^{1,2 \dagger}$, Hamed Majidzadeh ${ }^{4}$, Chen $\mathrm{He}^{5}$, Quan Shi ${ }^{5}$, \\ Sifang Kong ${ }^{6}$, Zhibing Yang ${ }^{2}$ and Junjian Wang ${ }^{1,2 *}$
}

\begin{abstract}
${ }^{1}$ State Environmental Protection Key Laboratory of Integrated Surface Water-Groundwater Pollution Control, School of Environmental Science and Engineering, Southern University of Science and Technology, Shenzhen, China, ${ }^{2}$ Guangdong Provincial Key Laboratory of Soil and Groundwater Pollution Control, School of Environmental Science and Engineering, Southern University of Science and Technology, Shenzhen, China, ${ }^{3}$ State Key Laboratory of Water Resources and Hydropower Engineering Science, Wuhan University, Wuhan, China, ${ }^{4}$ Environmental and Physical Science Department, Southern New Hampshire University, Manchester, NH, United States, ${ }^{5}$ State Key Laboratory of Heavy Oil Processing, College of Chemical Engineering, China University of Petroleum, Beijing, China, ${ }^{6}$ Department of Transportation and Environment, Shenzhen Institute of Information Technology, Shenzhen, China
\end{abstract}

\section{OPEN ACCESS}

Edited by:

Mengyang You,

Northeast Institute of Geography and Agroecology (CAS), China

Reviewed by:

Yanhong Wang,

Guizhou University of Traditional Chinese Medicine, China

Meng Zhou,

Northeast Institute of Geography and Agroecology (CAS), China

*Correspondence: Junjian Wang wangjj@sustech.edu.cn

${ }^{+}$These authors have contributed equally to this work

Specialty section: This article was submitted to Soil Processes,

a section of the journal Frontiers in Environmental Science

Received: 25 May 2021 Accepted: 09 July 2021 Published: 21 July 2021

Citation:

Wang Y, Zhang Q, Majidzadeh $H$, He C, Shi Q, Kong S, Yang Z and Wang J (2021) Depletion of Soil WaterExtractable Organic Matter With Long-

Term Coverage by

Impervious Surfaces.

Front. Environ. Sci. 9:714311. doi: 10.3389/fenvs.2021.714311
Water-extractable organic matter (WEOM) in soil is the critical substrate that fuels microbialdriven biogeochemical cycles. However, questions remain regarding whether and how expanding impervious surface area under global urbanization may alter soil WEOM cycling. Based on absorbance and fluorescence spectroscopy and Fourier transform ion cyclotron resonance mass spectrometry (FT-ICR MS), we compared the content and chemical signatures of soil WEOM under impervious surfaces with those in adjoining open areas and evaluated the impacts of types (complete sealing by concrete and partial sealing by house structures) and durations (1.5, 27, and 114 years) of impervious surface coverage. The content of soil WEOM and its chromophoric and fluorescent fractions were not significantly changed (less than 20\%) after 1.5 years of coverage by concrete and house structures. However, these parameters decreased by more than 30\% with 27 and 114 years of coverage by the residential home structures. The microbial-humic-like and protein-like fluorescent WEOM persisted preferentially over the terrestrial-humic-like and nonfluorescent WEOM. FT-ICR MS results suggest various degrees of depletion of biochemical groups in WEOM. While the water-extractable lipid-like compounds increased with 1.5 years of coverage, all studied biochemical groups were depleted with long-term coverage, which might reduce the microbial processing of suberinderived compounds. This study highlights the remarkable impacts of soil sealing on reducing substrate availability for microbial carbon processing in urban environments.

Keywords: urbanization, impervious surface, water-extractable organic matter, FT-ICR MS, time-dependent change

\section{INTRODUCTION}

Soil organic matter (SOM) is a critical regulator of the global carbon cycle, and its water-extractable fraction is referred to as soil-derived dissolved organic matter (DOM) or water-extractable organic matter (WEOM), which represents the most mobile and active carbon pool of SOM (Kalbitz et al., 2000; Bolan et al., 2011). WEOM is the main source of carbon and energy for soil microorganisms and regulates the carbon cycle and associated nutrient cycles (Wu et al., 2018) and also an important 
carrier of nutrients and pollutants that actively regulate soil and water quality (Aiken et al., 2011; Fu et al., 2018). Soil WEOM is involved in many environmental biogeochemical processes and has different fates and functions depending on its chemical properties (Bolan et al., 2011). Therefore, the properties of WEOM are important indicators of soil quality (Bongiorno et al., 2019). The chemodiversity of WEOM has been related to soil physical-chemical properties and soil microbial community characteristics (Roth et al., 2019; Ding et al., 2020). Anthropogenic irruptions, such as global warming, increased nitrogen deposition, and frequently occurring fires, could also alter the composition of WEOM (Dittmar et al., 2012; Fröberg et al., 2013; Wang et al., 2019).

With the development of the global economy, urban land is expanding at an unprecedented pace (Chen et al., 2020b). Impervious surfaces, such as roads, roofs, and parking lots, are anthropogenic features in urban environments that keep water from filtrating into the soil (Scalenghe and Marsan, 2009). The global impervious surface area in 2010 was estimated to account for $60 \%$ of the global urban area and will continuously increase in future decades (Kuang, 2019). Constructions of impervious surfaces strongly impact soil functions in urban ecosystems by landscape renovation (Scalenghe and Marsan, 2009). Soils under impervious surfaces encounter soil sealing and compaction, which will inevitably decrease organic matter mobility and seem to benefit the conservation of soil organic carbon (SOC). Nevertheless, with no plant carbon inputs, many studies have reported a $26-74 \%$ decrease in SOC content under impervious surfaces compared with soil in open areas (Yan et al., 2015; Cambou et al., 2018), and the SOM became depleted in carbohydrate components and enriched in suberin- and lignin-derived carbon (Wang et al., 2020). As soils under impervious surfaces could have elevated soil temperature and reduced soil aeration compared to soils with vegetation coverage (Scalenghe and Marsan, 2009), the soil microbial community tends to shift and drive the selective depletion of SOC (Piotrowska-Długosz and Charzyński, 2014; $\mathrm{Hu}$ et al., 2018). Impervious surfaces could increase the surface runoff and decrease the infiltration (Lorenz and Lal, 2009). Soil hydrological conditions can strongly influence the export of soil DOM not only in quantity but also in quality (Mead et al., 2013). WEOM under impervious surfaces is expected to change in response to limited water filtration and microbial community changes, which, however, remaining untested. Revealing how WEOM content and signatures change under impervious surfaces will be essential for understanding the biogeochemical cycle of organic carbon in urban ecosystems.

The construction of impervious surfaces usually involves topsoil removal (Piotrowska-Długosz and Charzyński, 2014; Yan et al., 2015). Ignoring the impacts of the initial disturbances may overestimate the impact of impervious surface coverage on soil properties. Comparing two types of reference soils $(0-10 \mathrm{~cm}$ and $10-20 \mathrm{~cm})$ and soils under impervious surfaces (soil originally $10-20 \mathrm{~cm}$ and now $0-10 \mathrm{~cm}$ because the top $10-\mathrm{cm}$ soil was removed) allow more accurate assessment of the sealing impacts on soil properties such as soil moisture, temperature, and nutrients (Majidzadeh et al., 2018). Based on this setting, we previously investigated how different types and durations of impervious surface coverage impact SOM content and signatures using ${ }^{13} \mathrm{C}$ nuclear magnetic resonance and specific biomarker analyses. Depletion in carbohydrates and an increase in aromatics in SOM composition were found in soils under impervious surfaces, and such an alteration was greater with coverage by concrete slabs (complete sealing) than home structures built on crawl spaces (partial sealing that allows some air and moisture ventilation) and was greater as the duration of coverage by residential home structures increased (Wang et al., 2020). However, how the content and signatures of WEOM, the most active part of SOM, would vary with the type and duration of impervious surface coverage remains unknown.

In this study, we applied optical analysis, including absorption and fluorescence spectroscopy, to capture the chemical changes of WEOM. We also used Fourier transform ion cyclotron resonance mass spectrometry (FTICR MS) to track the molecular-level signatures of WEOM. The objectives of this study were to 1) evaluate the changes of soil WEOM content and composition in response to the coverage of different types of impervious surfaces, and 2) reveal the different responses to the short- ( 1.5 years) and long-term (17 and 114 years) coverage by home structures. We will provide a fundamental understanding of the biogeochemical cycling of organic carbon under impervious surfaces.

\section{MATERIALS AND METHODS}

\section{Site Description and Sample Collection}

The controlled field experiment site was located at Auburn, Alabama, the United States. The soil at the site was classified as an Acrisol according to World Reference Base for Soil Resources (IUSS Working Group WRB, 2015). The mean annual air temperature and mean precipitation were $17.4^{\circ} \mathrm{C}$ and $1,337 \mathrm{~mm}$, respectively, and two types of impervious surfaces were constructed on the grassland in October 2014. A detailed description can be found in the research of Majidzadeh et al. (2018). Briefly, concrete slabs and simulated home buildings on a crawl space (hereafter denoted as "simulated home structures") were used to represent impervious surfaces that result in poor and well-aerated conditions, respectively. After the removal of grasses and the top $10 \mathrm{~cm}$ of soil, impervious surfaces were set up in four random plots $\left(5 \times 5 \mathrm{~m}^{2}\right.$ in size). Four open grassland plots nearby without impervious surface coverage were used as references. After 1.5 years of coverage, four replicate samples from each treatment plot were collected at a depth of $0-10 \mathrm{~cm}$, which was originally the $10-20 \mathrm{~cm}$ layer before topsoil removal. From the reference plots, both the $0-10 \mathrm{~cm}$ and $10-20 \mathrm{~cm}$ soil layers were collected and used as the surface reference (Surf-ref) and the subsurface reference (Sub-ref).

Soils under existing homes built on a crawl space (denoted as "residential home structures") were also collected in residential 
areas in Auburn, Alabama (Majidzadeh et al., 2017). The soil type was the same as in the field site. Duplicate soil samples from the $0-10 \mathrm{~cm}$ depth were collected from 27-year-old and 114-year-old residential home structures to represent the long-term coverage of impervious surfaces on decadal and century scales, respectively. Home age information was obtained from the city of Auburn Planning Commission and Lee County Courthouse, Opelika, Alabama. The homes we sampled (similar to most homes in that area) did not have a basement or a foundation and were built on a concrete slab. Topsoil removal was thus limited and was approximately $10 \mathrm{~cm}$ based on personal communications with homeowners and local contractors.

\section{Water Extractable Organic Carbon Concentration Analysis and Optical Characterization}

Soil WEOM was extracted in precombusted glass bottles with a modified procedure based on Chantigny et al. (2014). A total of $5.0 \mathrm{~g}$ soil was added to $100 \mathrm{ml}$ of Milli-Q water and shaken at $200 \mathrm{rpm}$ for $2 \mathrm{~h}$ at $20^{\circ} \mathrm{C}$. The suspension was fully filtered through a $0.45 \mu \mathrm{m}$ polyethersulfone membrane (Millipore). The filtrate was stored in the dark at $4^{\circ} \mathrm{C}$ prior to further analyses.

Aliquots of water extracts were added to precombusted $24 \mathrm{ml}$ glass vials, acidified to $\mathrm{pH} 2$ by $6 \mathrm{~N}$ hydrochloric acid, and analyzed for the organic carbon concentration using a combustion method on a total organic carbon analyzer [TOCL CSN, Shimadzu, Japan; (Stubbins et al., 2015)]. The coefficient of variance was lower than 2\% with 3-5 injections for each sample. The water-extractable organic carbon content per dry soil mass (noted as "WEOC concentration" in this study; in $\mathrm{mg} \mathrm{C} / \mathrm{g} \mathrm{dws}$ ) was calculated to indicate the quantity of WEOM.

Ultraviolet-visible absorbance spectra and fluorescence matrices were collected simultaneously over an Aqualog ${ }^{\circledR}$ spectrophotometer (Horiba, Japan). The sample was placed in an acid-cleaned $10 \mathrm{~mm}$ quartz cell, and the spectra were collected with excitation (Ex) and emission (Em) wavelengths of 240-450 and $240-550 \mathrm{~nm}$ in 3 and $1 \mathrm{~nm}$ increments, respectively. The integration time was set as $0.5 \mathrm{~s}$. To minimize temperature and inner filter effects, all the samples were analyzed at constant laboratory temperature and diluted if the absorbance at $254 \mathrm{~nm}$ $\left(\mathrm{A}_{254}\right)$ was higher than 0.1 (Murphy et al., 2013).

Absorbance and fluorescence data were processed and calculated for the spectroscopic indices to characterize the WEOM properties. Carbon-specific ultraviolet absorbance at $254 \mathrm{~nm}\left(\mathrm{SUVA}_{254}\right)$ was calculated by dividing $A_{254}$ by the DOC concentration and reported in units of liters per milligram carbon per meter to indicate the WEOM aromaticity (Weishaar et al., 2003). The spectral slope between 275 and $295 \mathrm{~nm}$ was calculated $\left(\mathrm{S}_{275-295}\right)$ to evaluate the relative molecular size across samples (Helms et al., 2008). The absorption coefficient at $350 \mathrm{~nm}\left(\mathrm{a}_{350}\right)$ was used to indicate the abundance of chromophoric dissolved organic matter (CDOM) (Spencer et al., 2013). All EEMs were blanksubtracted, corrected for inner-filter effects, and further normalized to Raman units. PARAFAC modeling was performed using MATLAB with the drEEM toolbox (Murphy et al., 2013). The number of components was validated based on split-half analysis, and a three-component model was established. Similar to $\mathrm{SUVA}_{254}$, the carbon-specific fluorescence intensity of each component was calculated as Fmax divided by the WEOC concentration to indicate the relative abundance of each component per milligram WEOC (noted as $\mathrm{C}_{\mathrm{OrgC}}$ $\mathrm{C} 3 \operatorname{orgC}_{\text {C }}$. The fluorescence index (FI) was determined as the ratio of the fluorescence intensity at Em $470 \mathrm{~nm}$ to that at $520 \mathrm{~nm}$ when Ex was $370 \mathrm{~nm}$ (McKnight et al., 2001). The biological index (BIX), calculated as the ratio of Em intensity at $380 \mathrm{~nm}$ to the maximum Em between 420 and $435 \mathrm{~nm}$ when Ex was $310 \mathrm{~nm}$ (Wilson and Xenopoulos, 2009), was used to assess changes in the fluorescent components.

\section{Fourier Transform Ion Cyclotron Resonance Mass Spectrometry Analysis}

The WEOM was solid-phase extracted (SPE) by an Agilent Bond Elut PPL cartridge (100 mg PPL in $3 \mathrm{ml}$ cartridge) following the method of Spencer et al. (2014). Briefly, the PPL cartridges were rinsed with methanol, Milli-Q water, and then $0.01 \mathrm{M}$ formic acid. A calculated volume of formic acid-acidified samples was loaded on the cartridge at a flow rate of $0.5 \mathrm{ml}$ per minute. Aliquot volumes of samples were calculated based on WEOC concentration and adjusted based on a conservative average SPE recovery of $40 \%$ to obtain a target content of $50 \mu \mathrm{g} \mathrm{C}$. The cartridge was then rinsed with $0.01 \mathrm{M}$ formic acid again to elute out the inorganics and was dried with ultrahigh purity nitrogen gas. WEOM was eluted with $2.5 \mathrm{ml} \mathrm{GC-MS}$ grade methanol. The WEOM was analyzed in negative electrospray ionization mode using a 9.4 Tesla FT-ICR MS (Bruker, Germany) with a standard method developed by Chen et al. (2020a). A total of 128 broadband scans between $\mathrm{m} / z 200$ and 800 were accumulated for each analysis. Mass peaks with signal-to-noise ratios greater than 6 were considered for formula assignment following compositional constraints: ${ }^{12} \mathrm{C}_{1-60},{ }^{1} \mathrm{H}_{1-120},{ }^{16} \mathrm{O}_{0-30}$, ${ }^{14} \mathrm{~N}_{0-3}$, and ${ }^{32} \mathrm{~S}_{0-1}$. The mass accuracy window was set to $1.0 \mathrm{ppm}$. The modified aromaticity index (AImod) and double-bond equivalent (DBE) values were calculated, and the intensity was weighted to reveal the molecular-level characteristics of WEOM (Kellerman et al., 2018). Assigned formulae were classified into $\mathrm{CHO}, \mathrm{CHON}, \mathrm{CHOS}$, and CHONS elemental groups and categorized into seven biochemical groups based upon their elemental composition (Kim et al., 2003; Wu et al., 2018), which included 1) lipidlike $(1.5 \leq \mathrm{H} / \mathrm{C} \leq 2.3,0 \leq \mathrm{O} / \mathrm{C} \leq 0.2$, and $\mathrm{N} / \mathrm{C} \leq 0.04)$, 2) peptidelike $(1.5 \leq \mathrm{H} / \mathrm{C} \leq 2.2,0.2 \leq \mathrm{O} / \mathrm{C} \leq 0.52$, and $0.178 \leq \mathrm{N} / \mathrm{C} \leq 0.44)$, 3) amino sugar-like $(1.5 \leq \mathrm{H} / \mathrm{C} \leq 2.2,0.52 \leq \mathrm{O} / \mathrm{C} \leq 0.7$, and $0.07 \leq$ $\mathrm{N} / \mathrm{C} \leq 0.182), 4)$ carbohydrate-like $(1.5 \leq \mathrm{H} / \mathrm{C} \leq 2.4,0.7 \leq \mathrm{O} / \mathrm{C} \leq$ 1.1 , and $n=0$ ), 5) dissolved black carbon-like (AImod $\geq 0.67$ and $\mathrm{C} \geq 15), 6)$ lignin-like (0.75 $\leq \mathrm{H} / \mathrm{C} \leq 1.5$ and $0.25 \leq \mathrm{O} / \mathrm{C} \leq 0.67)$, and 7$)$ tannin-like $(0.53 \leq \mathrm{H} / \mathrm{C} \leq 1.5$ and $0.67 \leq \mathrm{O} / \mathrm{C} \leq 0.97)$. The relative abundance of each elemental group and biochemical group was calculated in terms of formula numbers. In addition, the estimated percent change in WEOM component $i$ under impervious surfaces relative to the reference soil was calculated as the estimated content of WEOM 

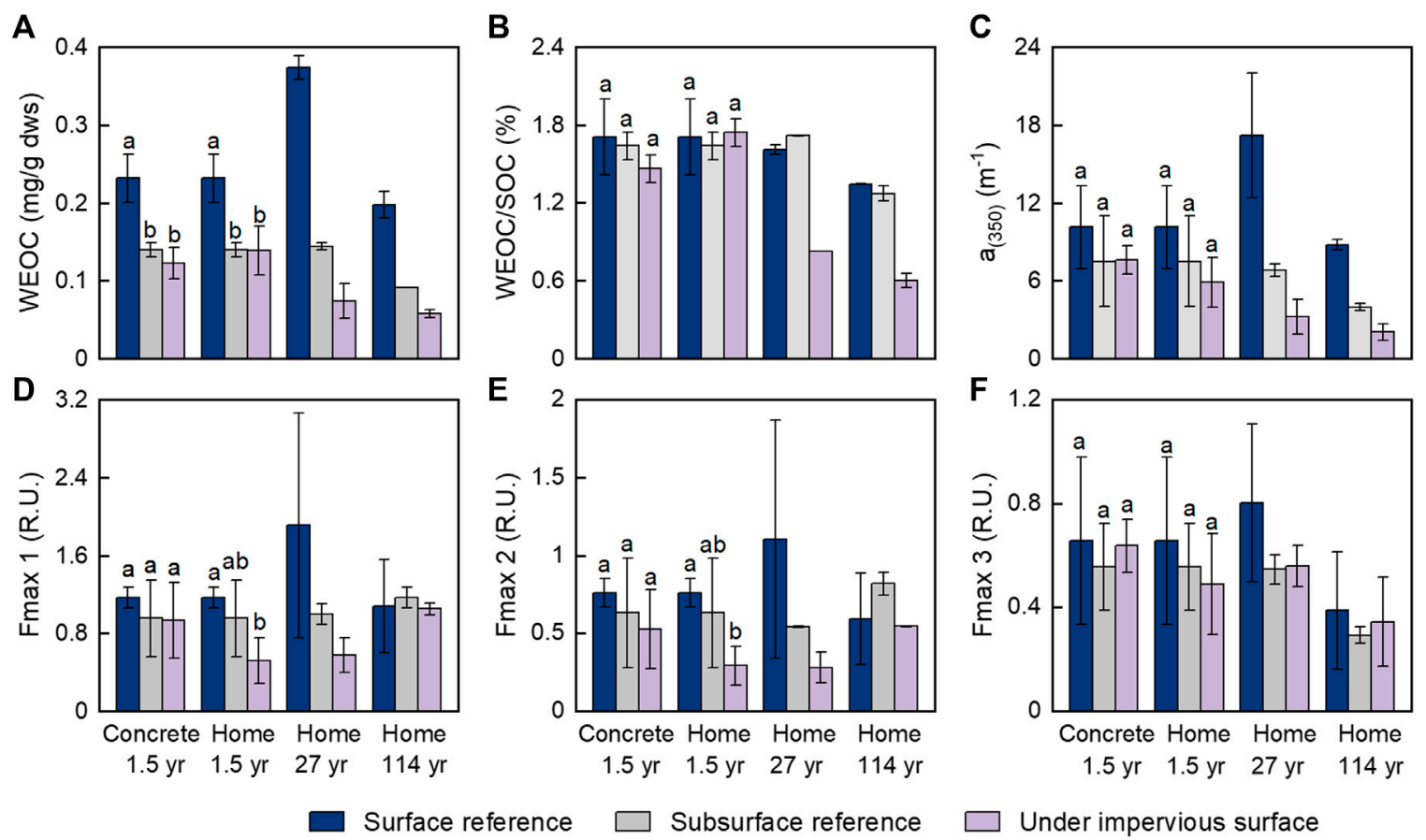

FIGURE 1 | The variation in dissolved organic carbon in soils with and without coverage by impervious surfaces. (A) Total dissolved organic carbon concentration; (B) relative content of the dissolved organic carbon to the soil organic carbon; (C) abundance of the chromophoric dissolved organic matter; (D-F) intensities of the three components of the fluorescent dissolved organic matter. Surface and subsurface references are surface (0-10 cm) soils and subsurface (10-20 cm) soils from nearby open areas without coverage by impervious surfaces. Treatment groups are soils with impervious surface coverage, which include 1.5 years of coverage by concrete slabs and simulated home structures and 27 and 114 years of coverage by residential home structures built on crawl spaces. For the concrete-1.5 years and home-1.5 years groups, error bars represent the SD $(n=4)$, lowercase letters indicate significantly different groups $(p<0.05)$. For the other two groups, error bars represent the average deviation $(n=2)$.

component $i$ (relative abundance of component $i$ multiplied by WEOC concentration) in soils under impervious surfaces divided by that in reference soil and subtracted by $100 \%$ (Wang et al., 2019).

\section{Statistical Analyses and Data Processing}

The differences among sample groups (soils under impervious surface and their Surf-ref or Sub-ref) of the field-controlled experiment were assessed using one-way analysis of variance (ANOVA) with Tukey's HSD test. The limited sample number of real residential land $(n=2)$ did not allow us to make a satisfactory statistical analysis. Therefore, we defined operationally that there was a "considerable difference" when the numerical ranges between the treatment and the reference groups did not overlap and the percentage change of the average value of WEOM parameter of soil under impervious surface relative to that of reference soil was $>20 \%$ or $<-20 \%$.

\section{RESULTS AND DISCUSSION}

\section{Variation in DOC Stocks Under Impervious Surface Coverage}

The soils under impervious surfaces had much lower WEOM content than the Surf-ref, as indicated by WEOC concentrations
(Figure 1A). The WEOC concentrations were 47 and $40 \%$ lower in soils with 1.5 years of coverage by concrete slabs and simulated home structures than in Surf-ref and did not differ between the two different types of impervious surfaces. However, they were not significantly different compared to those in the Sub-ref. For the soils with 27 and 114 years of coverage by the residential home structures, the WEOC concentrations were 80 and $71 \%$ lower than those in their related Surf-ref and 48 and 37\% lower than their respective Sub-ref.

Although the WEOC concentration was considerably lower in Sub-ref than in Surf-ref due to the lower SOC content in Sub-ref, the WEOC/SOC did not significantly differ between Surf-ref and Sub-ref (Figure 1B). With 1.5 years of coverage by impervious surfaces, WEOC/SOC did not change significantly compared to Surf-ref or Sub-ref. However, the WEOC/SOC decreased by approximately half $(48-55 \%)$ with 27 and 114 years of coverage regardless of which reference soil was used (Figure 1B). These results imply that blocking fresh plant inputs on a yearly scale may not result in significant WEOC depletion, but doing so on decadal or century scales. This is probably because even without fresh plant inputs, extra WEOC could be temporarily released via desorption processes or microbial production to supplement WEOC consumption and degradation in soils under impervious surfaces (Wang et al., 2017). However, desorption or microbial production of WEOC 

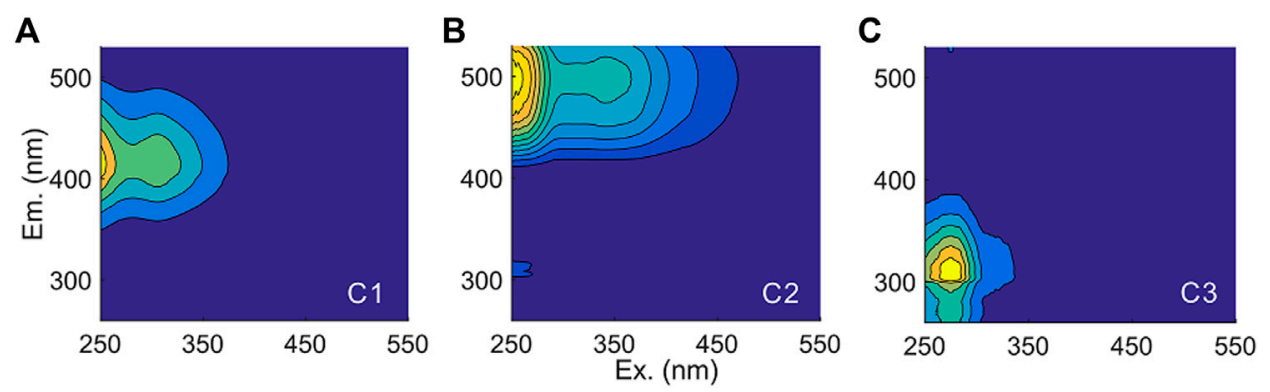

FIGURE 2 | Fluorescence spectra of three PARAFAC components identified in this study.

would become weaker with increasing time, and thus, there would be a net loss of WEOC on a long-term scale. As WEOC is the most active part of the SOC to provide essential carbon and energy to microbes (Wu et al., 2018), the decreases in WEOC concentration and the WEOC/SOC ratio explain well the decreased activity of microbes under impervious surfaces (Wei et al., 2013; Hu et al., 2018). While microbial activity was suppressed, the microbial capacities for processing various SOM components were inevitably altered. Indeed, our previous study on the same sites found considerable preservation of suberin-derived compounds in SOM with 114 years of impervious surface coverage (Wang et al., 2020). Similarly, a 20-year-long litter removal manipulation experiment showed that limited fresh litter and root inputs caused the accumulation of suberin-derived compounds (Wang et al., 2017).

Chromophoric dissolved organic matter (CDOM) is an important portion of dissolved organic matter with many conjugated and aromatic structures and is hypothesized to be sensitive to photochemical degradation but relatively resistant to microbial degradation (Li and Hur, 2017; Spencer et al., 2009). The absorption coefficient at $350 \mathrm{~nm}$ is often used as a proxy for the abundance of CDOM (Spencer et al., 2013). The results showed that CDOM (indicated by $\mathrm{a}_{350}$ ) was more abundant in Surf-ref than in Sub-ref (Figure 1C), which may have been caused by the higher WEOC concentration and more phenol components from plant and litter leachates in the surface soil than in subsurface soil (Stubbins et al., 2017; Ye et al., 2020). The $\mathrm{a}_{350}$ in soils with 1.5 years of coverage by concrete slabs or simulated home structures was lower than that in Surf-ref but similar to that in Sub-ref. The $\mathrm{a}_{350}$ in soils with 27 and 114 years of coverage by the residential home structures were 81 and $76 \%$ lower than those in Surf-ref and 52 and $48 \%$ lower than those in Sub-ref. The percent decreases in CDOM were similar to those in WEOC, which suggests that at the long-term scale, the CDOM was consumed to similar extents as the nonchromophoric DOM. This finding suggests that CDOM can also be biodegradable and serve as an important carbon source for microbes on a long-term scale (Cory and Kaplan, 2012).

A fraction of CDOM is fluorescent and is commonly referred to as fluorescent DOM (FDOM). PARAFAC analysis of the excitation-emission matrix and comparison with OpenFluor validated three fluorescence components in our samples
(Figure 2, Murphy et al. (2014)). Component 1 had an excitation maximum $<250 \mathrm{~nm}$ (secondary at $310 \mathrm{~nm}$ ) and an emission maximum at $420 \mathrm{~nm}$ and can be classically described as a microbial-humic-like fluorescence component related to biological activity; component 2 [ex $<260$ (350) and em: $495 \mathrm{~nm}$ ] was redshifted terrestrial-humic-like fluorescence; component 3 (ex: 270; em: 305) is similar to tyrosine-like fluorescence (Fellman et al., 2010; Kellerman et al., 2018). Humic-like components $\mathrm{C} 1$ and $\mathrm{C} 2$ contributed the most to the fluorescence intensity. Most of the Fmax values of each component derived from the same mass of soil did not show significant decreases in response to coverage by impervious surfaces (Figures 1D-F), except for the considerably decreased Fmax values of $\mathrm{C} 2$ after 27 and 114 years of impervious surface coverage. This result indicated that FDOM could be more resistant to biogeochemical processing than nonfluorescent CDOM and nonchromophoric DOM; in addition, terrestrialhumic-like $\mathrm{C} 2$ could be preferentially consumed over microbialhumic-like $\mathrm{C} 1$ and protein-like $\mathrm{C} 3$ in FDOM on long-term scales.

\section{Variations in the Spectroscopic Characteristics of WEOM}

Spectroscopic characteristics provided additional information about the impacts of impervious surface coverage on soil WEOM chemistry. SUVA is commonly used to indicate the relative abundance of aromatic materials or CDOM within the total WEOC (Weishaar et al., 2003). SUVA, an indicator of WEOM aromaticity, did not show any consistent trend with impervious surface coverage (Figure 3A). Therefore, the relative abundance of aromatic WEOM in the total WEOM pool remained relatively stable because of the simultaneous decreases in nonchromophoric WEOM and CDOM (mostly aromatic WEOM) with the long-term coverage of impervious surfaces. As a high $\mathrm{S}_{275-295}$ reflects relatively low molecular size, soil with 1.5 years of coverage by concrete slabs and simulated home structures appeared to have a lower molecular size of WEOM (indicated by higher $\mathrm{S}_{275-295}$ ) than that of Surf-ref but similar molecular size of WEOM to that of Sub-ref (Figure 3E). However, soils with 27 and 114 years coverage with home structures appeared to have higher molecular sizes of WEOM (indicated by lower $\mathrm{S}_{275-295}$ ) than Surf-ref and Sub-ref. The 

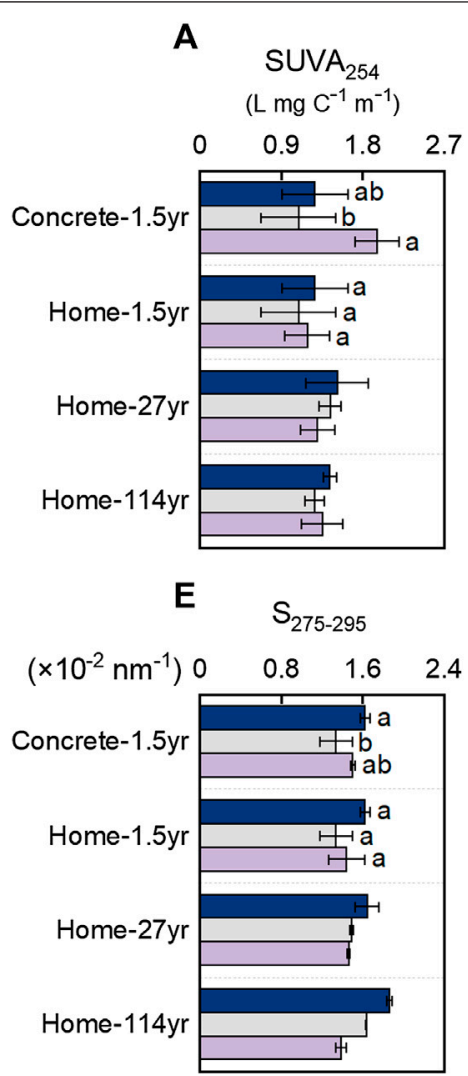

B $\begin{aligned} & \mathrm{C} 1_{\text {OrgC }} \\ & \text { (R.U. mg C }\end{aligned}$

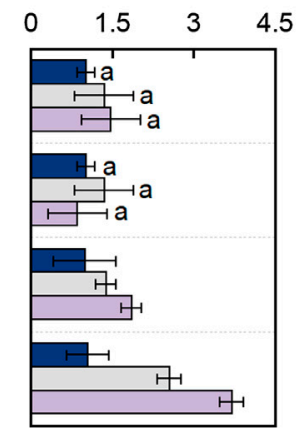

F
$\mathrm{BIX}$

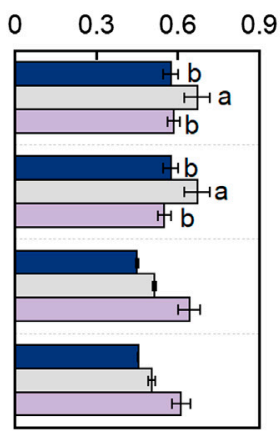

C

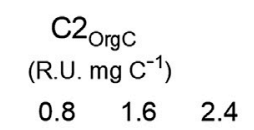

D

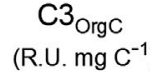

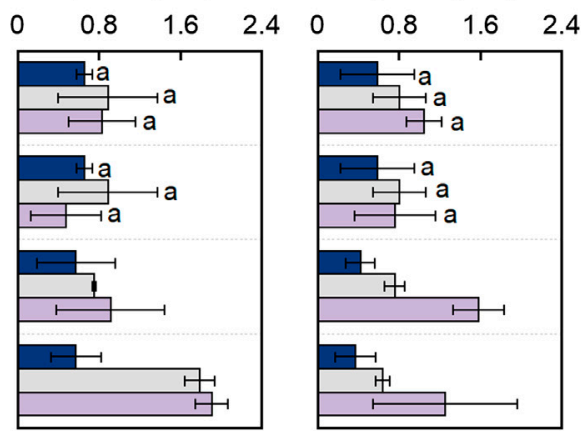

G

FI

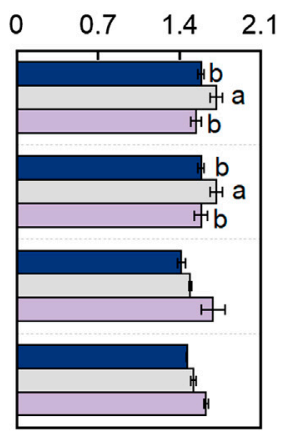

Surface reference

Subsurface reference

Under impervious surface

FIGURE 3 | Spectroscopic characteristics of dissolved organic matter in soils with and without coverage by impervious surfaces. (A) SUVA 254 , specific ultraviolet absorbance at $254 \mathrm{~nm}$; (B-D) $\mathrm{C1}_{\text {Orgc }}-\mathrm{C}_{\text {Orgc }}$ relative abundance of fluorescent components per total dissolved organic carbon; (E) $\mathrm{S}_{275-295}$, the absorbance slope between 275 and $295 \mathrm{~nm}$; (F) BIX, biological index; (G) FI, fluorescence index.

increased molecular size of WEOM in soils with long-term coverage of impervious surfaces than Sub-ref might be due to preferential utilization of low-molecular-weight carbohydrates, organic acids, and peptides, which are more accessible to microbes (Hansen et al., 2016).

The relative abundance of each fluorescence component in the total dissolved organic carbon $\left(\mathrm{C}_{\mathrm{OrgC}}, \mathrm{C} 2_{\mathrm{OrgC}}\right.$, and $\left.\mathrm{C} 3_{\mathrm{OrgC}}\right)$ in soils increased with long-term impervious surface coverage. In soils with 27 and 114 years of home structure coverage, $\mathrm{Cl}_{\mathrm{OrgC}}$ was 86 and $251 \%$ higher than that in Surf-ref and 34 and $45 \%$ higher than that in Sub-ref, respectively. Similar to $\mathrm{C} 1_{\operatorname{OrgC}}$, $\mathrm{C} 33_{\text {OrgC }}$ in soils with 27 and 114 years of coverage by home structures were almost tripled than those in Surf-ref and doubled compared to those in Sub-ref. However, different from $\mathrm{C} 1_{\mathrm{OrgC}}$ and $\mathrm{C} 3_{\mathrm{OrgC}}, \mathrm{C} 2_{\mathrm{OrgC}}$ was not considerably increased in soils with 27 and 114 years of home structure coverage compared to their respective Sub-ref values. The Fmax and relative abundances of three components consistently indicate that the FDOM was more persistent than the nonfluorescent CDOM. Among the FDOM, the terrestrialhumic-like component $\mathrm{C} 2$ was most depleted, followed by the microbial-humic-like component $\mathrm{C} 1$ and the protein-like component C3. The microbe-related fluorescent $\mathrm{C} 1$ and $\mathrm{C} 3$ were persistent, probably due to their efficient recycling between living and dead microbes (Kellerman et al., 2015; Liang et al., 2019). Rather than being recalcitrant to microbial utilization, local turnover could be the main reason for the increases in $\mathrm{Cl}_{\mathrm{OrgC}}$ and $\mathrm{C} 3_{\mathrm{OrgC}}$ when the amount of WEOM decreased. BIX and FI are often used to indicate contributions from newly produced microbe-related components. Consistent with the greater persistence of $\mathrm{C} 1$ and $\mathrm{C} 3$ than $\mathrm{C} 2$, both BIX and FI increased considerably in soils with 27 and 114 years of home structure coverage and indicated greater microbial contributions in the WEOM.

\section{Compositional Changes in Soil WEOM From a Molecular Perspective}

FT-ICR MS captured molecular-level signatures of WEOM in soils with and without coverage of impervious surfaces. More than 4,300 molecular formulae were assigned to each soil sample (Table 1). CHO formulae were identified as the most abundant group (47-56\%), followed by $\mathrm{CHON}$ and $\mathrm{CHOS}$. Consistent with the $\mathrm{S}_{275-295}$ results, the average molecular weight of WEOM increased from $349 \mathrm{Da}$ in Sub-ref to $407 \mathrm{Da}$ in soils with 114 years of home structure coverage, which could be 
TABLE 1 | Molecular characterization of the solid-phase extracted WEOM in soils with and without coverage by impervious surfaces.

\begin{tabular}{|c|c|c|c|c|c|c|c|c|c|c|c|c|}
\hline \multirow[t]{2}{*}{ Parameters } & \multicolumn{3}{|c|}{ Concrete-1.5 years } & \multicolumn{3}{|c|}{ Home-1.5 years } & \multicolumn{3}{|c|}{ Home-27 years } & \multicolumn{3}{|c|}{ Home-114 years } \\
\hline & Under IM & Surf-ref & Sub-ref & Under IM & Surf-ref & Sub-ref & Under IM & Surf-ref & Sub-ref & Under IM & Surf-ref & Sub-ref \\
\hline No. of assigned formulae & 5,428 & 5,966 & 6,182 & 5,853 & 5,966 & 6,182 & 5,344 & 5,025 & 4,964 & 5,567 & 4,318 & 4,807 \\
\hline Average $\mathrm{m} / \mathrm{z}$ & 404.11 & 378.10 & 406.46 & 390.75 & 378.10 & 406.46 & 411.45 & 367.72 & 420.28 & 407.12 & 353.63 & 349.30 \\
\hline Average $\mathrm{H} / \mathrm{C}$ & 1.08 & 1.32 & 1.09 & 1.15 & 1.32 & 1.09 & 1.24 & 1.32 & 1.16 & 1.14 & 1.32 & 1.47 \\
\hline Average O/C & 0.51 & 0.42 & 0.50 & 0.48 & 0.42 & 0.50 & 0.46 & 0.42 & 0.50 & 0.49 & 0.44 & 0.37 \\
\hline Average DBE & 9.83 & 7.59 & 9.85 & 9.07 & 7.59 & 9.85 & 8.68 & 7.43 & 9.53 & 9.45 & 7.02 & 5.93 \\
\hline Average $\mathrm{Al}_{\text {mod }}$ & 0.35 & 0.25 & 0.35 & 0.32 & 0.25 & 0.35 & 0.27 & 0.26 & 0.31 & 0.32 & 0.25 & 0.19 \\
\hline$\% \mathrm{CHO}$ & 52.67 & 46.82 & 50.86 & 51.99 & 46.82 & 50.86 & 48.43 & 53.35 & 55.32 & 52.97 & 55.84 & 53.30 \\
\hline$\% \mathrm{CHON}$ & 38.08 & 39.94 & 38.22 & 39.98 & 39.94 & 38.22 & 33.89 & 34.95 & 31.18 & 30.34 & 31.59 & 32.35 \\
\hline$\% \mathrm{CHOS}$ & 8.73 & 12.30 & 9.50 & 8.03 & 12.30 & 9.50 & 11.99 & 6.99 & 9.99 & 12.04 & 7.55 & 8.78 \\
\hline$\% \mathrm{CHONS}$ & 0.52 & 0.94 & 1.42 & 0.00 & 0.94 & 1.42 & 5.69 & 4.72 & 3.51 & 4.65 & 5.03 & 5.58 \\
\hline \% Lipid-like & 1.95 & 2.41 & 1.20 & 2.20 & 2.41 & 1.20 & 1.72 & 3.00 & 1.49 & 1.19 & 3.38 & 3.95 \\
\hline \% Peptide-like & 0.42 & 1.22 & 0.73 & 0.96 & 1.22 & 0.73 & 1.03 & 1.83 & 1.13 & 0.38 & 1.81 & 1.56 \\
\hline \% Amino sugar-like & 0.41 & 0.96 & 0.63 & 0.72 & 0.96 & 0.63 & 1.09 & 0.92 & 0.91 & 0.84 & 0.90 & 1.10 \\
\hline \% Carbohydrate-like & 0.63 & 1.68 & 1.33 & 1.30 & 1.68 & 1.33 & 0.41 & 1.75 & 0.87 & 0.54 & 1.39 & 1.00 \\
\hline \% Dissolved BC-like & 1.84 & 4.21 & 2.54 & 2.19 & 4.21 & 2.54 & 6.34 & 4.80 & 3.51 & 4.80 & 3.50 & 5.03 \\
\hline \% Lignin-like & 52.49 & 55.41 & 53.96 & 53.05 & 55.41 & 53.96 & 56.36 & 47.82 & 54.21 & 55.15 & 43.96 & 42.23 \\
\hline$\%$ Tannin-like & 12.44 & 5.36 & 10.97 & 9.40 & 5.36 & 10.97 & 5.61 & 5.41 & 9.37 & 8.28 & 9.52 & 5.60 \\
\hline
\end{tabular}

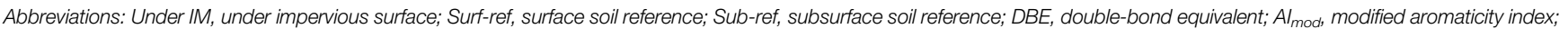
Dissolved BC-like, dissolved black carbon-like.

explained by the preferential use of small molecules. Other bulk characteristics of WEOM, such as double-bond equivalent and modified aromaticity index based on FT-ICR MS analysis did not show a consistent trend in soils with short- and long-term coverage of impervious surfaces, which could be attributed to no significant alteration in WEOM aromaticity (indicated by SUVA $_{254}$ ).

The molecular composition of WEOM showed various changes with the coverage of impervious surfaces (Figure 4). Compared to Surf-ref, soils with 1.5 years of coverage by impervious surfaces had decreased abundances of all biochemical groups except tannin-like compounds. When compared to Sub-ref, they had a decreased abundance of carbohydrate-like compounds and an increased abundance of lipid-like compounds, and the decrease in soluble carbohydrate-like compounds was greater in soils with coverage by concrete slabs than home structures built on crawl spaces. The increases in soluble lipidlike compounds could be due to the contribution from the apoptosis of microbes and release of soluble microbial byproducts (Majidzadeh et al., 2018). In addition, the decreases in soluble carbohydrate-like components, particularly when the soil was covered by concrete, are consistent with our previous findings that the total carbohydrates in SOM were depleted and that greater depletion occurred with concrete coverage than with home structure coverage (Wang et al., 2020).

Different from the 1.5 years of coverage by home structures, the 27 and 114 years of coverage by home structures led to the consumption of all seven biochemical groups and greater consumption of carbohydrate-like formulae (Figure 4). The greater consumption of carbohydrates with a longer duration of coverage is consistent with our previous findings on changes in SOM components (Wang et al., 2020), which showed a depletion of carbohydrates and preservation of suberin-derived components with long-term coverage of home structures. Moreover, although condensed aromatics are often believed to be resistant to microbial degradation (Marschner and Kalbitz, 2003), they all showed decreased abundance in soils under impervious surfaces regardless of which reference soils were used. Therefore, under carbohydrate-limited conditions, aromatic compounds could also be used to maintain the biogeochemical cycle (Liang et al., 2019), and the transformation of aromatic components during the biodegradation process is actively (Wang et al., 2021).

\section{Future Implications}

Previous studies have stressed the potential risks of expanding impervious surfaces due to changes in soil physical and chemical properties, such as the urban heat island effect and water quality degradation (Brabec et al., 2002; Scalenghe and Marsan, 2009). Our study highlights the changes in the content and chemical signatures of the soil WEOM in response to the coverage of impervious surfaces. Due to the limited carbon inputs, the biogeochemical process in soils was preferentially maintained by WEOM over other SOM components. However, the assessment of the degree of WEOM losses largely depended on the reference groups. Specifically, using the surface reference instead of the subsurface reference could cause a $32-39 \%$ overestimation of WEOM loss due to long-term impervious surface coverage. Therefore, identifying the proper reference soil from the corresponding soil depth is very important in objectively evaluating the impacts of coverage by impervious surfaces. Nevertheless, depletion in labile WEOM under impervious surfaces would lead to low soil quality and a weak microbial community structure. The coverage of impervious surfaces had negative consequences for carbon conservation, and the impacts could be much stronger as the coverage duration increases. Sustainable developments with a focus on the resilience of the ecosystem should be given more attention. 


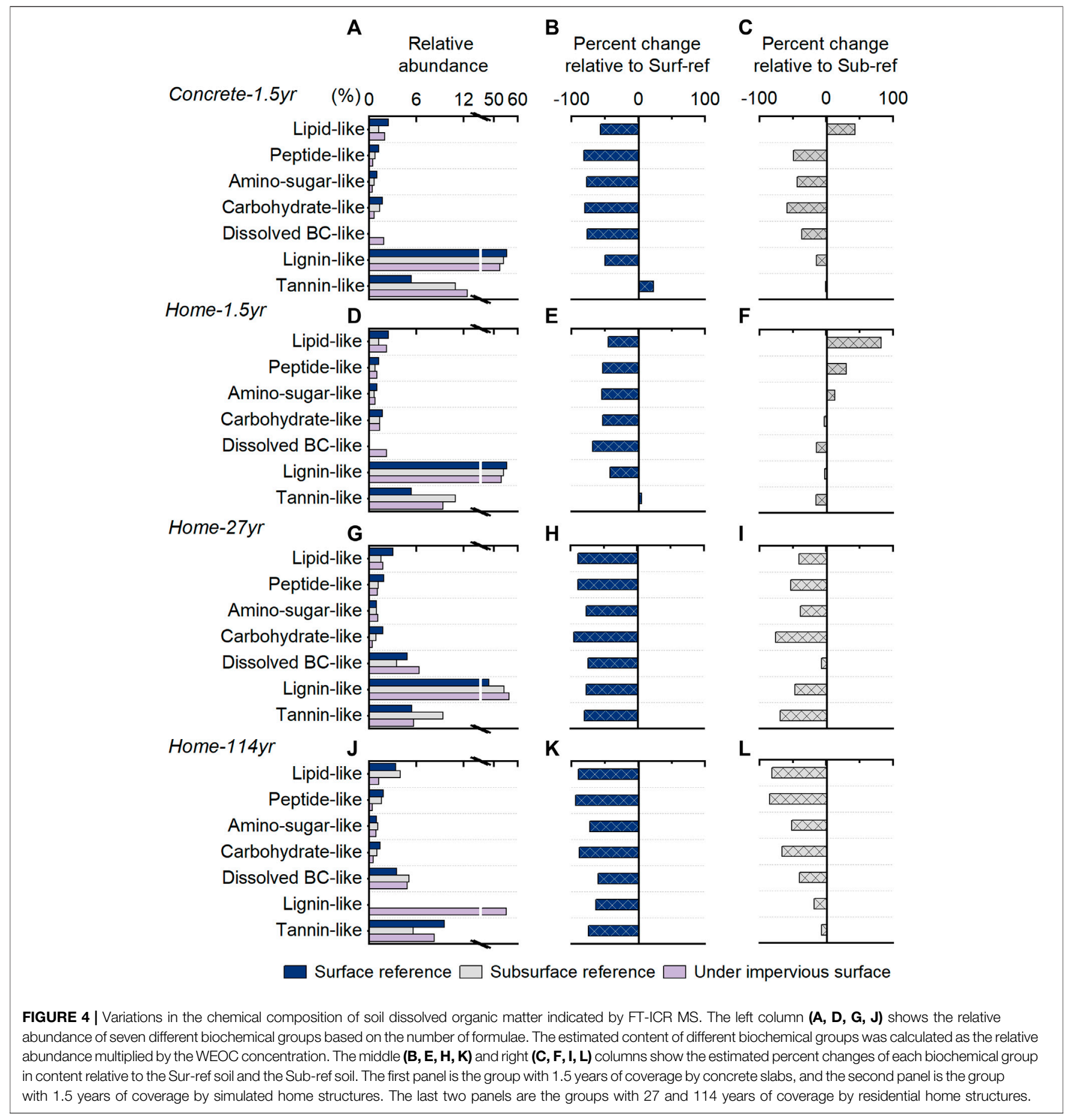

Implementation of pervious concrete and other low-impact development that maximize water infiltration is urgent and essential.

\section{CONCLUSION}

This study revealed the hitherto unknown impacts of impervious surfaces on soil WEOM, the critical substrate fueling microbial-driven biogeochemical processes. The WEOC content and its abundance in SOC (i.e., WEOC/SOC) in soils covered by impervious surfaces was not significantly depleted on a yearly scale but was depleted by $37-53 \%$ on a decadal or century scale. This highlights the importance of WEOM in maintaining the long-term biogeochemical cycle in soils with limited carbon inputs. Based on the optical properties, we found that CDOM could also be involved in microbial activity, but protein-like and microbial-humic-like FDOM have relatively high persistence. The molecular signatures of WEOM 
confirmed the selective consumption of carbohydrates within the short term and all soluble biochemical types in the long term, which means high substrate deletion for microbial processing of other SOM components. We highlight the need for long-term evaluation of anthropogenic disturbances. Additionally, beyond the SOM and WEOM, the related microbial community should be further investigated to obtain a comprehensive understanding of the biogeochemical cycle of SOM in soils covered with impervious surfaces.

\section{DATA AVAILABILITY STATEMENT}

The original contributions presented in the study are included in the article/Supplementary Material, further inquiries can be directed to the corresponding author.

\section{AUTHOR CONTRIBUTIONS}

JW conceived the study and obtained the funding. HM designed the controlled field experiment sites and collected the samples.

\section{REFERENCES}

Aiken, G. R., Hsu-Kim, H., and Ryan, J. N. (2011). Influence of Dissolved Organic Matter on the Environmental Fate of Metals, Nanoparticles, and Colloids. Environ. Sci. Technol. 45 (8), 3196-3201. doi:10.1021/es103992s

Bolan, N. S., Adriano, D. C., Kunhikrishnan, A., James, T., McDowell, R., Senesi, N., et al. (2011). "Dissolved Organic Matter,". Editor D. L. Sparks (San Diego: Elsevier Academic Press Inc), 1-75. doi:10.1016/b978-0-12385531-2.00001-3

Bongiorno, G., Bünemann, E. K., Oguejiofor, C. U., Meier, J., Gort, G., Comans, R., et al. (2019). Sensitivity of Labile Carbon Fractions to Tillage and Organic Matter Management and Their Potential as Comprehensive Soil Quality Indicators across Pedoclimatic Conditions in Europe. Ecol. Indicators 99, 38-50. doi:10.1016/j.ecolind.2018.12.008

Brabec, E., Schulte, S., and Richards, P. L. (2002). Impervious Surfaces and Water Quality: A Review of Current Literature and its Implications for Watershed Planning. J. Plann. Lit. 16 (4), 499-514. doi:10.1177/088541202400903563

Cambou, A., Shaw, R. K., Huot, H., Vidal-Beaudet, L., Hunault, G., Cannavo, P., et al. (2018). Estimation of Soil Organic Carbon Stocks of Two Cities, New York City and Paris. Sci. Total Environ. 644, 452-464. doi:10.1016/ j.scitotenv.2018.06.322

Chantigny, M. H., Harrison-Kirk, T., Curtin, D., and Beare, M. (2014). Temperature and Duration of Extraction Affect the Biochemical Composition of Soil Water-Extractable Organic Matter. Soil Biol. Biochem. 75, 161-166. doi:10.1016/j.soilbio.2014.04.011

Chen, C., Hall, S. J., Coward, E., and Thompson, A. (2020a). Iron-mediated Organic Matter Decomposition in Humid Soils Can Counteract protection. Nat. Commun. 11 (1), 2255. doi:10.1038/s41467-020-16071-5

Chen, G., Li, X., Liu, X., Chen, Y., Liang, X., Leng, J., et al. (2020b). Global Projections of Future Urban Land Expansion under Shared Socioeconomic Pathways. Nat. Commun. 11 (1), 537. doi:10.1038/s41467-020-14386-x

Cory, R. M., and Kaplan, L. A. (2012). Biological Lability of Streamwater Fluorescent Dissolved Organic Matter. Limnol. Oceanogr. 57 (5), 1347-1360. doi:10.4319/lo.2012.57.5.1347

Ding, Y., Shi, Z., Ye, Q., Liang, Y., Liu, M., Dang, Z., et al. (2020). Chemodiversity of Soil Dissolved Organic Matter. Environ. Sci. Technol. 54 (10), 6174-6184. doi:10.1021/acs.est.0c01136

Dittmar, T., de Rezende, C. E., Manecki, M., Niggemann, J., Coelho Ovalle, A. R., Stubbins, A., et al. (2012). Continuous Flux of Dissolved Black Carbon from a
QZ, YW, and $\mathrm{CH}$ performed sample analyses. YW and QZ prepared the first draft, and all authors contributed to the revisions.

\section{FUNDING}

This work was financially supported by the National Natural Science Foundation of China (41807360), Guangdong Natural Science Funds for Distinguished Young Scholar (2021B1515020082), Key Platform and Scientific Research Projects of Guangdong Provincial Education Department (2018KTSCX199, 2019KZDXM028, 2019GKTSCX092, and 2020KCXTD006), and Shenzhen Science \& Technology Project (SZIITWDZC 2021A01, LHPY-2019017, and KJ 2020D018).

\section{SUPPLEMENTARY MATERIAL}

The Supplementary Material for this article can be found online at: https://www.frontiersin.org/articles/10.3389/fenvs.2021.714311/ full\#supplementary-material

Vanished Tropical forest Biome. Nat. Geosci 5 (9), 618-622. doi:10.1038/ ngeo1541

Fellman, J. B., Hood, E., and Spencer, R. G. M. (2010). Fluorescence Spectroscopy Opens New Windows into Dissolved Organic Matter Dynamics in Freshwater Ecosystems: A Review. Limnol. Oceanogr. 55 (6), 2452-2462. doi:10.4319/ lo.2010.55.6.2452

Fröberg, M., Grip, H., Tipping, E., Svensson, M., Strömgren, M., and Kleja, D. B. (2013). Long-term Effects of Experimental Fertilization and Soil Warming on Dissolved Organic Matter Leaching from a spruce forest in Northern Sweden. Geoderma 200-201, 172-179. doi:10.1016/j.geoderma.2013.02.002

Fu, H., Wei, C., Qu, X., Li, H., and Zhu, D. (2018). Strong Binding of Apolar Hydrophobic Organic Contaminants by Dissolved Black Carbon Released from Biochar: A Mechanism of Pseudomicelle Partition and Environmental Implications. Environ. Pollut. 232, 402-410. doi:10.1016/j.envpol.2017.09.053

Hansen, A. M., Kraus, T. E. C., Pellerin, B. A., Fleck, J. A., Downing, B. D., and Bergamaschi, B. A. (2016). Optical Properties of Dissolved Organic Matter (DOM): Effects of Biological and Photolytic Degradation. Limnol. Oceanogr. 61 (3), 1015-1032. doi:10.1002/lno.10270

Helms, J. R., Stubbins, A., Ritchie, J. D., Minor, E. C., Kieber, D. J., and Mopper, K. (2008). Absorption Spectral Slopes and Slope Ratios as Indicators of Molecular Weight, Source, and Photobleaching of Chromophoric Dissolved Organic Matter. Limnol. Oceanogr. 53 (3), 955-969. doi:10.4319/lo.2008.53.3.0955

Hu, Y., Dou, X., Li, J., and Li, F. (2018). Impervious Surfaces Alter Soil Bacterial Communities in Urban Areas: A Case Study in Beijing, China. Front. Microbiol. 9, 226. doi:10.3389/fmicb.2018.00226

IUSS Working Group WRB. (2015). World reference base for soil resources 2014: International soil classification system for naming soils and creating legends for soil maps. World Soil Resources Reports No. 106. FAO, Rome.

Kalbitz, K., Solinger, S., Park, J.-H., Michalzik, B., and Matzner, E. (2000). Controls on the Dynamics of Dissolved Organic Matter in Soils: A Review. Soil Sci. 165 (4), 277-304. doi:10.1097/00010694-200004000-00001

Kellerman, A. M., Guillemette, F., Podgorski, D. C., Aiken, G. R., Butler, K. D., and Spencer, R. G. M. (2018). Unifying Concepts Linking Dissolved Organic Matter Composition to Persistence in Aquatic Ecosystems. Environ. Sci. Technol. 52 (5), 2538-2548. doi:10.1021/acs.est.7b05513

Kellerman, A. M., Kothawala, D. N., Dittmar, T., and Tranvik, L. J. (2015). Persistence of Dissolved Organic Matter in Lakes Related to its Molecular Characteristics. Nat. Geosci 8 (6), 454-457. doi:10.1038/Ngeo2440

Kim, S., Kramer, R. W., and Hatcher, P. G. (2003). Graphical Method for Analysis of Ultrahigh-Resolution Broadband Mass Spectra of Natural Organic Matter, 
the Van Krevelen Diagram. Anal. Chem. 75 (20), 5336-5344. doi:10.1021/ ac034415p

Kuang, W. (2019). Mapping Global Impervious Surface Area and green Space within Urban Environments. Sci. China Earth Sci. 62 (10), 1591-1606. doi:10.1007/s11430-018-9342-3

Li, P., and Hur, J. (2017). Utilization of UV-Vis Spectroscopy and Related Data Analyses for Dissolved Organic Matter (DOM) Studies: A Review. Crit. Rev. Environ. Sci. Tech. 47 (3), 131-154. doi:10.1080/10643389.2017.1309186

Liang, C., Amelung, W., Lehmann, J., and Kästner, M. (2019). Quantitative Assessment of Microbial Necromass Contribution to Soil Organic Matter. Glob. Change Biol. 25 (11), 3578-3590. doi:10.1111/gcb.14781

Lorenz, K., and Lal, R. (2009). Biogeochemical C and N Cycles in Urban Soils. Environ. Int. 35 (1), 1-8. doi:10.1016/j.envint.2008.05.006

Majidzadeh, H., Lockaby, B. G., and Governo, R. (2017). Effect of home Construction on Soil Carbon Storage-A Chronosequence Case Study. Environ. Pollut. 226, 317-323. doi:10.1016/j.envpol.2017.04.005

Majidzadeh, H., Lockaby, B. G., Price, R., and Governo, R. (2018). Soil Carbon and Nitrogen Dynamics beneath Impervious Surfaces. Soil Sci. Soc. America J. 82 (3), 663-670. doi:10.2136/sssaj2017.11.0381

Marschner, B., and Kalbitz, K. (2003). Controls of Bioavailability and Biodegradability of Dissolved Organic Matter in Soils. Geoderma 113 (3-4), 211-235. doi:10.1016/S0016-7061(02)00362-2

McKnight, D. M., Boyer, E. W., Westerhoff, P. K., Doran, P. T., Kulbe, T., and Andersen, D. T. (2001). Spectrofluorometric Characterization of Dissolved Organic Matter for Indication of Precursor Organic Material and Aromaticity. Limnol. Oceanogr. 46 (1), 38-48. doi:10.4319/lo.2001.46.1.0038

Mead, R. N., Mullaugh, K. M., Brooks Avery, G., Kieber, R. J., Willey, J. D., and Podgorski, D. C. (2013). Insights into Dissolved Organic Matter Complexity in Rainwater from continental and Coastal Storms by Ultrahigh Resolution Fourier Transform Ion Cyclotron Resonance Mass Spectrometry. Atmos. Chem. Phys. 13 (9), 4829-4838. doi:10.5194/acp-13-4829-2013

Murphy, K. R., Stedmon, C. A., Graeber, D., and Bro, R. (2013). Fluorescence Spectroscopy and Multi-Way Techniques. PARAFAC. Anal. Methods 5 (23), 6557-6566. doi:10.1039/c3ay41160e

Murphy, K. R., Stedmon, C. A., Wenig, P., and Bro, R. (2014). OpenFluor- an Online Spectral Library of Auto-Fluorescence by Organic Compounds in the Environment. Anal. Methods 6 (3), 658-661. doi:10.1039/c3ay41935e

Piotrowska-Długosz, A., and Charzyński, P. (2014). The Impact of the Soil Sealing Degree on Microbial Biomass, Enzymatic Activity, and Physicochemical Properties in the Ekranic Technosols of Torun (Poland). J. Soils Sediments 15 (1), 47-59. doi:10.1007/s11368-014-0963-8

Roth, V.-N., Lange, M., Simon, C., Hertkorn, N., Bucher, S., Goodall, T., et al. (2019). Persistence of Dissolved Organic Matter Explained by Molecular Changes during its Passage through Soil. Nat. Geosci. 12 (9), 755-761. doi:10.1038/s41561-019-0417-4

Scalenghe, R., and Marsan, F. A. (2009). The Anthropogenic Sealing of Soils in Urban Areas. Landscape Urban Plann. 90 (1-2), 1-10. doi:10.1016/ j.landurbplan.2008.10.011

Spencer, R. G. M., Aiken, G. R., Dornblaser, M. M., Butler, K. D., Holmes, R. M., Fiske, G., et al. (2013). Chromophoric Dissolved Organic Matter export from U.S. Rivers. Geophys. Res. Lett. 40 (8), 1575-1579. doi:10.1002/grl.50357

Spencer, R. G. M., Guo, W., Raymond, P. A., Dittmar, T., Hood, E., Fellman, J., et al. (2014). Source and Biolability of Ancient Dissolved Organic Matter in Glacier and lake Ecosystems on the Tibetan Plateau. Geochimica et Cosmochimica Acta 142, 64-74. doi:10.1016/j.gca.2014.08.006

Spencer, R. G. M., Stubbins, A., Hernes, P. J., Baker, A., Mopper, K., Aufdenkampe, A. K., et al. (2009). Photochemical Degradation of Dissolved Organic Matter and Dissolved Lignin Phenols from the Congo River. J. Geophys. Res. 114, 12. doi:10.1029/2009jg000968

Stubbins, A., Silva, L. M., Dittmar, T., and Van Stan, J. T. (2017). Molecular and Optical Properties of Tree-Derived Dissolved Organic Matter in Throughfall and Stemflow from Live oaks and Eastern Red Cedar. Front. Earth Sci. 5 (22). doi:10.3389/feart.2017.00022

Stubbins, A., Spencer, R. G. M., Mann, P. J., Holmes, R. M., McClelland, J. W., Niggemann, J., et al. (2015). Utilizing Colored Dissolved Organic Matter to Derive Dissolved Black Carbon export by Arctic Rivers. Front. Earth Sci. 3 (63). doi:10.3389/feart.2015.00063

Wang, J.-J., Liu, Y., Bowden, R. D., Lajtha, K., Simpson, A. J., Huang, W.-L., et al. (2019). Long-term Nitrogen Addition Alters the Composition of Soil-Derived Dissolved Organic Matter. ACS Earth Space Chem. 4 (2), 189-201. doi:10.1021/ acsearthspacechem.9b00262

Wang, J.-J., Pisani, O., Lin, L. H., Lun, O. O. Y., Bowden, R. D., Lajtha, K., et al. (2017). Long-term Litter Manipulation Alters Soil Organic Matter Turnover in a Temperate Deciduous forest. Sci. Total Environ. 607-608, 865-875. doi:10.1016/j.scitotenv.2017.07.063

Wang, K., Pang, Y., Li, Y., He, C., Shi, Q., Wang, Y., et al. (2021). Characterizing Dissolved Organic Matter across a Riparian Soil-Water Interface: Preliminary Insights from a Molecular Level Perspective. ACS Earth Space Chem. 5 (5), 1102-1113. doi:10.1021/acsearthspacechem.1 00029

Wang, Y.-H., Shi, Y.-M., Sun, G.-D., Li, J.-T., Chen, H., Chow, A. T., et al. (2020). Soil Organic Carbon Signature under Impervious Surfaces. ACS Earth Space Chem. 4 (10), 1785-1792. doi:10.1021/acsearthspacechem.0c00174

Wei, Z., Wu, S., Zhou, S., and Lin, C. (2013). Installation of Impervious Surface in Urban Areas Affects Microbial Biomass, Activity (Potential C Mineralisation), and Functional Diversity of the fine Earth. Soil Res. 51 (1), 59-67. doi:10.1071/ Sr12089

Weishaar, J. L., Aiken, G. R., Bergamaschi, B. A., Fram, M. S., Fujii, R., and Mopper, K. (2003). Evaluation of Specific Ultraviolet Absorbance as an Indicator of the Chemical Composition and Reactivity of Dissolved Organic Carbon. Environ. Sci. Technol. 37 (20), 4702-4708. doi:10.1021/es030360x

Wilson, H. F., and Xenopoulos, M. A. (2009). Effects of Agricultural Land Use on the Composition of Fluvial Dissolved Organic Matter. Nat. Geosci 2 (1), 37-41. doi:10.1038/ngeo391

Wu, X. Q., Wu, L. Y., Liu, Y., Zhang, P., Li, Q. H., Zhou, J. Z., et al. (2018). Microbial Interactions with Dissolved Organic Matter Drive Carbon Dynamics and Community Succession. Front. Microbiol. 9 (1234). doi:10.3389/fmicb.2018.01234

Yan, Y., Kuang, W. H., Zhang, C., and Chen, C. B. (2015). Impacts of Impervious Surface Expansion on Soil Organic Carbon - a Spatially Explicit Study. Sci. Rep. 5, (17905). doi:10.1038/srep17905

Ye, Q. H., Wang, Y. H., Zhang, Z. T., Huang, W. L., Li, L. P., Li, J. T., et al. (2020). Dissolved Organic Matter Characteristics in Soils of Tropical Legume and Nonlegume Tree Plantations. Soil Biol. Biochem. 148, 107880. doi:10.1016/ j.soilbio.2020.107880

Conflict of Interest: The authors declare that the research was conducted in the absence of any commercial or financial relationships that could be construed as a potential conflict of interest.

Copyright $\odot 2021$ Wang, Zhang, Majidzadeh, He, Shi, Kong, Yang and Wang. This is an open-access article distributed under the terms of the Creative Commons Attribution License (CC BY). The use, distribution or reproduction in other forums is permitted, provided the original author(s) and the copyright owner(s) are credited and that the original publication in this journal is cited, in accordance with accepted academic practice. No use, distribution or reproduction is permitted which does not comply with these terms. 